\title{
Hydrological Feasibility of Environmental Flows in the Rio Grande/Bravo Basin
}

\author{
Samuel Sandoval-Solis ${ }^{1}$ and Daene C. McKinney ${ }^{2}$ \\ ${ }^{1}$ Center for Research in Water Resources, University of Texas at Austin, Austin, TX \\ 78712; PH (512) 471-0071; FAX (512) 471-0072; \\ email: samuel.sandoval@mail.utexas.edu \\ ${ }^{2}$ Center for Research in Water Resources, University of Texas at Austin, Austin, TX \\ 78712; PH (512) 471-5644; FAX (512) 471-0072; email: daene@aol.com
}

\begin{abstract}
Due to high water demand, the scarcity of water resources, and the complexity of water allocation in the Rio Grande/Bravo basin, environmental flows have not been considered as an integral part of the water management in this basin. Important environmental habitats such as the Big Bend National Park in the US, the Northern Chihuahuan desert, the Maderas del Carmen and the Cañon de Santa Elena natural reserves in Mexico are ecologically threatened because of the lack of environmental water management policies in the basin. Several efforts have been undertaken by government agencies and non-governmental organizations in order to determine the environmental flows requirements for the basin. Even though environmental flows in several locations along the basin have been determined (e.g., the Rio Conchos tributary), the quantification and availability of the water necessary to provide these environmental flows has not been determined. In this paper we evaluate the hydrological feasibility of environmental flows in the Rio Conchos tributary to the Rio Grande. This evaluation is done in a basin model constructed in the Water Evaluation and Planning system (WEAP) software. An analysis of the available water has been defined to determine the amount of water required to provide the environmental flows. The description and evaluation of the environmental flows are presented along with a comparison against the current water management policies.
\end{abstract}

\section{Introduction}

The Rio Grande/Bravo basin is a transboundary basin between Mexico and the United States (U.S.). Historically, this basin has been manipulated in an exclusive human water resource management mode (Enriquez-Coyro, 1976), not considering the environmental needs of the native ecosystems. The Convention of 1906 signed between Mexico and the U.S. (IBWC 1906) and the Rio Grande Compact (TCEQ 1939) ratified in 1939 between the States of Colorado, New Mexico and Texas prove the fact that the water in this basin was thought to be used exclusively for human benefit. The water allocation in these agreements obeys exclusively the human concerns, leaving out the natural water requirements of the basin. As a result of the previous agreements, the quantity of water in the Rio Grande/Bravo reach between El Paso to Presidio Texas were reduced so dramatically, that this reach is now referred 
as the "forgotten river" where almost no water flows. Another example is the signature of the treaty of 1944 between Mexico and the U.S. (IBWC 1944). In this treaty, the environmental issues are not considered and the priority assigned to the environment is not even specified, leaving it in disadvantage with respect to the other water uses. In addition, because of the water scarcity in the basin and the high competition among water users for the resource, the environmental requirements has been denied or not even considered for a long time.

In 2002, a consortium of eight institutions integrated by universities, nongovernmental organizations (NGO's) and governmental research agencies from both countries was formed to assess the hydro-physical opportunities to improve the water management in the Rio Grande/Bravo basin. By conducting extensive interviews with water users, planning agencies, research institutes, NGO's and local, state and national government institutions the consortium defined a set of 33 scenarios that have some possibility to improve the water management in the basin (NHI 2001 and 2006, PAP 2006).

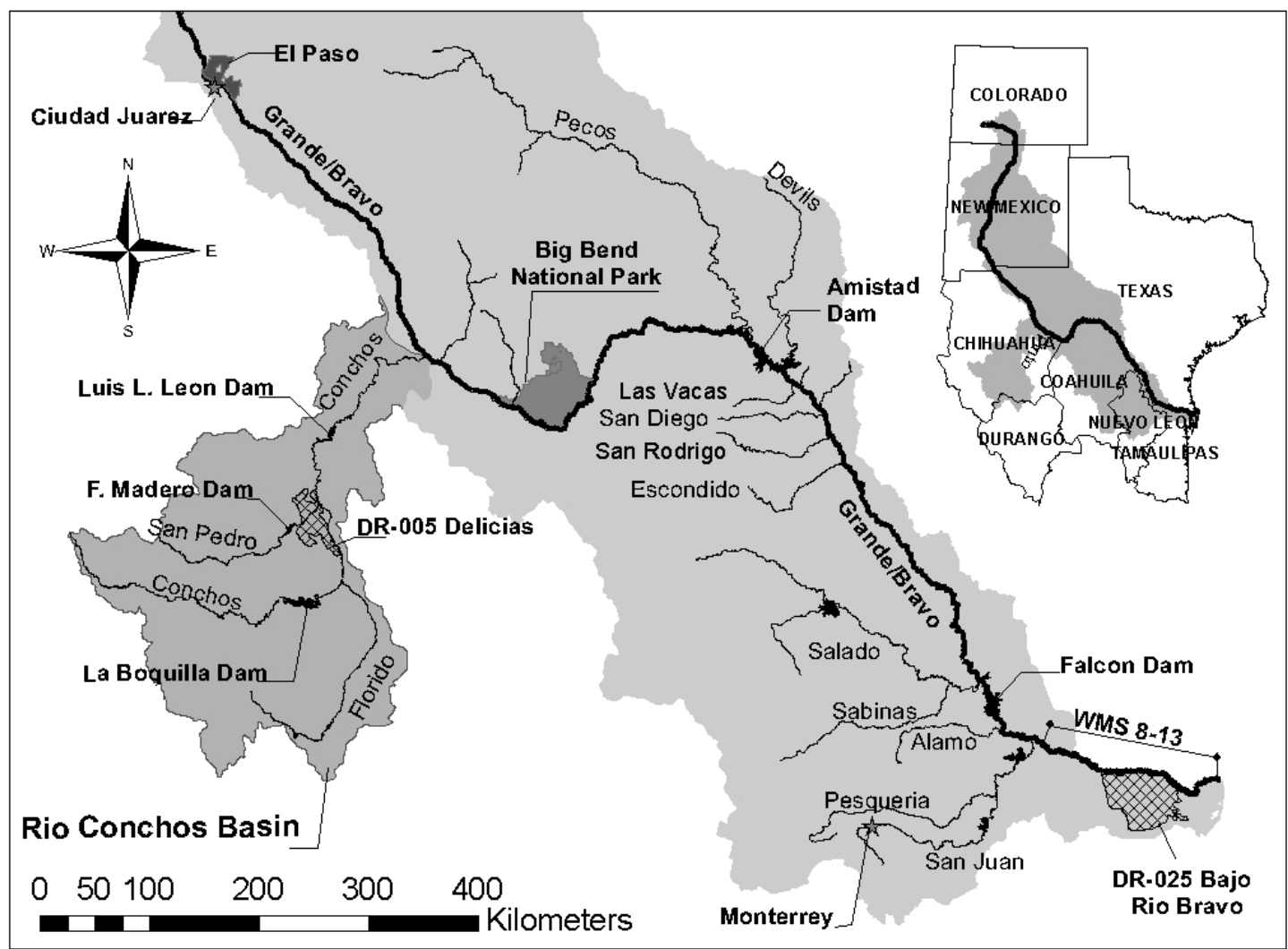

Figure 1. Rio Grande/Bravo Basin.

The aim of this paper is to present the results of one scenario that evaluates the hydrological feasibility of environmental flows in the Rio Conchos, a tributary of the Rio Grande/Bravo. This evaluation is done in a basin model constructed in the Water Evaluation and Planning system (WEAP) software. The description and 
evaluation of the environmental flows are presented along with a comparison against the current water management policies.

\section{Environmental flows in the Río Conchos Basin}

The Rio Conchos basin is a sub-basin of the Rio Grande/Bravo Basin, it has an area of 25,872 square miles $\left(67,008 \mathrm{Km}^{2}\right.$ ) (Patiño-Gomez and McKinney 2005) and is the main tributary to the Rio Grande/Bravo. Downstream the forgotten river reach, where almost no water flows in the Rio Grande/Bravo, Rio Conchos' waters revitalizes Rio Grande/Bravo at their confluence in Ojinaga/Presidio. Environmental flows downstream this point, such as the ones for the Big Bend National park, Maderas del Carmen and Cañon de Santa Elena natural reserves, depends on the water coming from the Rio Conchos.

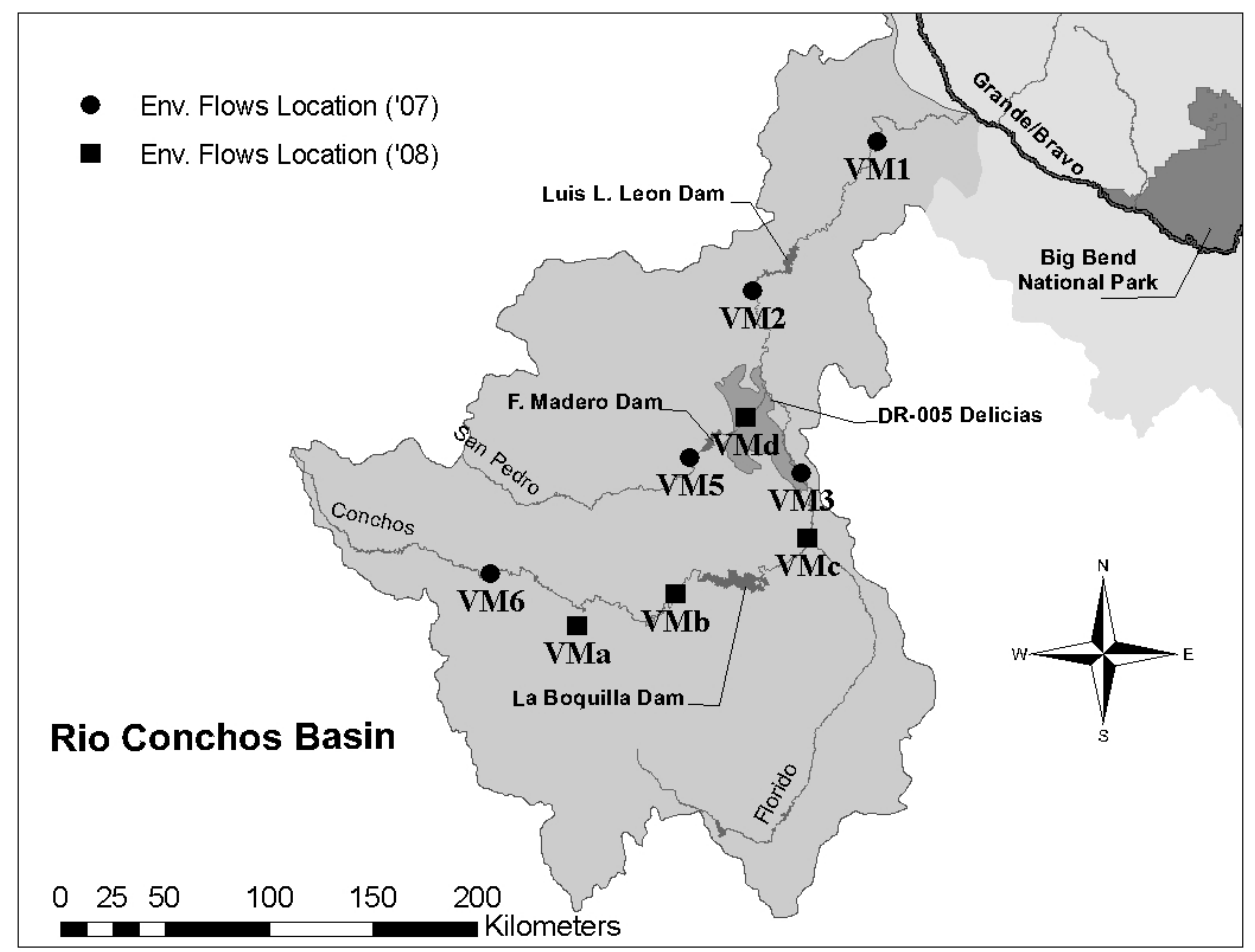

Figure 2. Environmental Flows Locations in the Rio Conchos Basin.

As part of an environmental flow assessment for the Rio Conchos, the World Wildlife Fund estimated the environmental flows in 9 locations along the Rio Conchos basin through the use of the Building Block Method (WWF 2006). The geomorphology, flora and fauna (fish and invertebrates) were considered to determine the maintenance and drought flows necessary to meet the environmental requirements. Figure 2 shows the location where the environmental flows were determined. Table 1 shows the name, stream and annual volume required for each location where environmental flows were defined. A monthly variation for each condition, maintenance or drought, was determined for each location. 
Table 1. Location of Environmental flow control points

\begin{tabular}{cllcc}
\hline & & & \multicolumn{2}{c}{$\begin{array}{c}\text { Environmental Flow } \\
\text { Maintenance }\end{array}$} \\
Site & \multicolumn{1}{c}{ Name } & \multicolumn{1}{c}{ River } & $\begin{array}{c}\text { Drought } \\
\left(1 \times 10^{6} \mathrm{~m}^{3} / \text { year }\right)\end{array}$ & $\left(1 \times 10^{6} \mathrm{~m}^{3} /\right.$ year $)$ \\
\hline VM1 & Cuchillo Parado & Conchos & 381.5 & 47.7 \\
VM2 & El Potrero & Conchos & 323.6 & 36.2 \\
VM3 & Estación Conchos & Conchos & 27.1 & 14.2 \\
VM5 & San Pedro de Conchos & San Pedro & 114.2 & 34.1 \\
VM6 & Agua Caliente & Conchos & 134.5 & 24.4 \\
VMc & Camargo & Conchos & 50.6 & 23.6 \\
VMd & C. Ortíz & San Pedro & 60.8 & 45.3 \\
\hline
\end{tabular}

One of the goals in this research is to determine if there is enough water in the basin to satisfy the environmental requirements at the locations selected and how much it affects other users in the basin. Ideally, we are looking for an alternative policy that meet the environmental needs without harming other water users, in other words, an alternative policy that is hydrologically feasible. In reality, it is necessary to evaluate several alternative water management policies and chose the one that brings the best tradeoffs between the delivery of water to the environment and the damages to other water users. Once the alternative policy is determined, more detailed operation policies must be developed to assess the facilities operation to meet the environmental flows in time, volume and space. The last assignment is out of the present research.

For this paper, 5 control points were selected to evaluate the environmental flow compliance at these locations: VM1 Cuchillo Parado, VM2 El Potrero, VM3 Estacion Conchos, VMc Camargo and VMd C. Ortiz. These control points were selected because they are spatially located downstream control structures, such as dams, that made available the intentional delivery of environmental flows to these locations. The control points $\mathrm{VMa}$ and $\mathrm{VMb}$ do not have any control structure that made possible the intentional delivery of environmental flows.

\section{Methodology}

The following methodology is proposed to evaluate the hydrological feasibility of environmental flows in the Rio Conchos basin.

1. An evaluation of the environmental flows proposed with the actual water management policies is done to identify the conflict points where the environmental requirements are more threatened.

2. An alternative operation policy is proposed.

3. The alternative operation policy is evaluated to determine if it improves the environmental requirements and how much this policy affects or benefits other water users in the basin. 
The Rio Grande/Bravo WEAP model was used to evaluate the actual and proposed water management policies in the Rio Conchos basin. The model has an hydrologic period of analysis of 60 years, form October 1940- to September 2000, it has been calibrated, validated (Danner et al. 2006) and it has been used to evaluate other alternative water managements policies (Sandoval-Solis et al. 2008).

\section{Status Quo of the Environmental flows in the Rio Conchos Basin}

A Baseline scenario that follows the actual policies of water management in the basin was constructed in the Rio Grande/Bravo WEAP model. The alternative water management policies will be compared with the Baseline scenario to evaluate the improvements in the system. Three performance criteria are used to evaluate the environmental flow compliance at each location: Reliability, Resilience and Vulnerability (Loucks and van Beek 2006). Reliability refers to the frequency in time an event is successful in relation to the total period of time analyzed (Hashimoto et al. 1982 and Klemes et al. 1981). We define a successful event as the event when there is no deficit in the delivery of environmental flows to the location in concern. Resilience is the probability that once the system is in a deficit, the next period the system recover to a successful event (Hashimoto et al. 1982). Vulnerability is the expected value of the deficits, in other words, it is the average deficit of environmental flows experienced (Hashimoto et al. 1982). For this paper, we are going to use the dimensionless vulnerability by dividing the average annual deficit by the environmental annual requirement (McMahon et al. 2006). These three performance criteria we are used to analyze the environmental flows.

\section{Table 2. Reliability Resilience and Vulnerability for the Baseline Scenario}

\begin{tabular}{lccc}
\hline Location & $\begin{array}{c}\text { Reliability } \\
(\%)\end{array}$ & $\begin{array}{c}\text { Resilience } \\
(\%)\end{array}$ & $\begin{array}{c}\text { Vulnerability } \\
(\%)\end{array}$ \\
\hline VM1 & 60 & 58 & 3 \\
VM2 & 42 & 37 & 9 \\
VM3 & 2 & 0 & 69 \\
VMc & 2 & 0 & 70 \\
VMd & 2 & 0 & 74 \\
\hline
\end{tabular}

Table 2 shows the reliability, resilience and vulnerability for the 5 control points selected with the actual water management conditions. For VM1, 60 percent of the time the environmental flows were met properly (Reliability); the average annual deficit to meet the environmental requirements is $3 \%$ (Vulnerability), and the probability of coming back from a deficit is 58\% (Resilience). For VM2, $42 \%$ of the time the environmental needs were delivered properly (Reliability), the average annual deficit is $9 \%$ of the environmental flow requirements and the probability of coming back from a deficit is $37 \%$. Notice that these two control points, which are located in the lower part of the Conchos basin, have the best results among the 5 
control points evaluated. For the control points VM3, VMc and VMd, located in the middle of the Conchos basin, only $2 \%$ of the time the environmental flows were met among the 60 year period of analysis, the average deficit to meet the environmental requirements was 69,70 and $74 \%$ respectively, and when the system fall into a deficit, it never come back again, $0 \%$ of Resilience. From these results is possible to affirm that the environmental flow are better accomplished in the lower Rio Conchos basin than in the middle and upper region.

\section{Environmental Flow Scenario}

The previous results showed that the conflict zones are located in the middle Conchos basin, at the control points VM3, VMc and VMd. As an initial approach, we propose an alternative water management policy that delivers water to the control points VMc and VMd. These control points are the most upstream control points to be analyzed and they are located just downstream La Boquilla and F. Madero reservoirs. Two reasons were considered for this decision. First, these are locations where water can be delivered properly from the dams in time and quantity, making the alternative policy operationally feasible. Second, we would like to evaluate if meeting the environmental requirements in the most upstream sites, it will provoke the rest of the control points downstream also meet their environmental requirements.

An analysis of La Boquilla-Francisco I. Madero reservoir system was done, in order to decide what kind of environmental flows, maintenance or drought, is allocated each year to the environment. First, at the beginning of each hydrological 0 ) in the reservoir system is estimated as the sum of the available storage in La $F M$ ). The available storage for each reservoir is calculated by subtracting the storage +Losses).

$F M$

+ Losses

+ Losses

Second, the diversion required to satisfy all the users from this reservoirs system is estimated. The diversion is calculated dividing the surface water right $(S W)$ from these reservoirs by the conveyance efficiency (Conv.Eff.) from the reservoir to the delivery point.

Conv.Eff.

Finally, the available storage is compared with the diversion. Based on this comparison a decision is made:

1. If the available storage is larger than the diversion, the maintenance flow is assigned, 
2. If the available storage is less than the diversion, the drought flow is assigned.

Droug $\square t$

The philosophy of this decision is that if the water users are expecting a shortage in their water supply, it is reasonable to ask only for the minimum volume of water for the environment, that in this case is the drought volume. If there is enough water in the reservoir system to supply properly all the water users, it is reasonable to ask for the normal flow for the environment than in this case is maintenance flow.

\section{Evaluation of the Environmental Flow Scenario}

Table 3 shows a comparison of the reliability, resilience and vulnerability between the Baseline and the Env. Flow scenario for the 5 control points selected. As can be seen, all the performance criteria were improved significantly. The reliability for all the points except of VMd is almost $100 \%$. This means that almost all the time the environmental flows were delivered at these locations. Similarly, the resilience follows in all the control points, except VMd, has a value of $100 \%$. This means that when a deficit happens in the environmental requirements, the next period the system recovers delivering the adequate water quantity to the environment. In addition, the vulnerability also decreased significantly almost to $0 \%$. This means that when a deficit in the environmental requirements happens, the quantity of the deficit is small, $0 \%$ in almost all locations and $4.6 \%$ at VMd downstream F. Madero.

Table 3. Comparison of the Reliability Resilience and Vulnerability between the Baseline and the Environmental Flow Scenario

\begin{tabular}{lcccccc}
\hline & \multicolumn{2}{c}{ Reliability } & \multicolumn{2}{c}{ Resilience } & \multicolumn{2}{c}{ Vulnerability } \\
Laseline Env. Flows & Baseline & Env. Flows & Baseline \\
Env. Flows & $(\%)$ & $(\%)$ & $(\%)$ \\
\hline VM1 & 60 & 100 & 58 & 100 & 3 & 0 \\
VM2 & 42 & 100 & 37 & 100 & 9 & 0 \\
VM3 & 2 & 97 & 0 & 100 & 69 & 0.3 \\
VMc & 2 & 97 & 0 & 100 & 70 & 0.2 \\
VMd & 2 & 78 & 0 & 46 & 74 & 4.6 \\
\hline
\end{tabular}

Even thought there is a significant improvement in the delivery of environmental flows in all the locations, the three points located in the middle Rio Conchos basin will not meet all the times the environmental requirements. For VM3 and VMc, the failures may be ignored since it has a reliability of $97 \%$ and an average deficit (Vulnerability) close to $0 \%(0.3 \%$ and $0.2 \%$ respectively). In contrast, the failures for VMd cannot be ignored, since $22 \%$ of the time the environmental flows will not be meet by an average of 5\%. These results show that during drought periods, 
there is not enough water in the La Boquilla - F. Madero reservoir system to satisfy the environmental minimum request that is the drought flow volume.

Now, let's evaluate how the implementation of the Environmental Flow scenario may affect or benefit other water users along the basin. For this purpose, the three biggest water user consumers were selected, two irrigation districts from Mexico, DR-005 Delicias and DR-025 Bajo Rio Bravo; and one irrigation district from the U.S., WMS-8-13 Agriculture "A". Table 4 shows the performance criteria results for these water users.

As can be seen, irrigation district DR-005 Delicias will be affected by the alternative policy proposed since the period of time this user was supplied properly (Reliability) will be reduced from $72 \%$ to $65 \%$. Besides, its average deficit (Vulnerability) increases from $36 \%$ to $48 \%$. These results were expected since DR005 Delicias relies on La Boquilla and F. Madero dams as its main source of water. In contrast, the performance of irrigation district DR-025 Bajo Rio Bravo improved since its reliability increases from 93 to $95 \%$. However, the Environmental scenario also increased the vulnerability for DR-025 Bajo Rio Bravo.

Table 4. Performance criteria for main water users

\begin{tabular}{lcccccc}
\hline & \multicolumn{2}{c}{ Reliability } & \multicolumn{2}{c}{ Resilience } & \multicolumn{2}{c}{ Vulnerability } \\
& Baseline & Env. Flows & Baseline & Env. Flows & Baseline & Env. Flows \\
WaterUser & $(\%)$ & $(\%)$ & $(\%)$ & $(\%)$ & $(\%)$ & $(\%)$ \\
\hline DR-005 & $\mathbf{7 2}$ & $\mathbf{6 5}$ & 29 & 29 & $\mathbf{3 6}$ & $\mathbf{4 8}$ \\
DR-025 & $\mathbf{9 3}$ & $\mathbf{9 5}$ & 25 & 25 & $\mathbf{2 5}$ & $\mathbf{2 9}$ \\
WMS 8-13 & 85 & 85 & 22 & 22 & 15 & 15 \\
Treaty & & & & & & \\
Obligations & 83 & 83 & 50 & 50 & $\mathbf{3 8}$ & $\mathbf{3 3}$ \\
\hline
\end{tabular}

Considering the distribution of water between Mexico and the U.S., the Treaty of 1944 (IBWC 1944) specifies the water distributions and allocation among both countries. In summary, for the Rio Grande/Bravo, Mexico has the obligation to deliver a volume of $431.721 \times 10^{6} \mathrm{~m}^{3}$ to the U.S. on average, per year in cycles of 5 consecutive years; this means a total of $2158.605 \times 10^{6} \mathrm{~m}^{3}$ per cycle. This volume must be achieved by $1 / 3$ of the waters reaching the main channel of the Rio Grande/Bravo from 6 Mexican tributaries (Rio Conchos, San Diego, San Rodrigo, Escondido, Salado and Arroyo Las Vacas). Results for the treaty obligations presented in Table 4 showed that the number of deficits will not be reduced (Reliability doesn't change), and the system will recover as fast as it does with the actual policy (Resilience does not change), however, there is an improvement in the reduction of the expected deficit amount (Vulnerability), from 38\% estimated with the actual policy to $33 \%$ estimated with the policies proposed in the Environmental Scenario. These results show that as a consequence of the policies proposed in the Environmental Scenario, the delivery of treaty obligation from Mexico to the U.S. will be improved. 


\section{Conclusions}

Results presented in this paper show the alarming situation of the environment in the Rio Grande/Bravo basin, specifically at the Conchos basin. The actual water management does not meet the environmental requirements by far. Results obtained in the Environmental Flow scenario showed a significant increase in meeting the environmental requirements in the Rio Conchos basin. Besides, the policies proposed also benefit the treaty obligations and water users located in the lower Rio Grande/Bravo basin, such as irrigation district 025 Bajo Rio Bravo. In contrast, the application of the Environmental Flow scenario will affect irrigation district 005 Delicias. These conclusions are discussed in detail as follows:

1. The actual environmental conditions in the basin are unsustainable. Results for the 5 control points evaluated with the actual water management show the lack of compliance of the environmental flows in the Rio Conchos basin. The area more affected is the middle Rio Conchos basin, where the environmental requirements are almost never met. In the lower Rio Conchos basin, the situation is better than in the middle basin but is still worrying. The analysis of the actual conditions let us determine the where the conflicts areas are in order to propose actions to solve the situation in these locations.

2. Results from the policies proposed in the Environmental Scenarios showed a significant improvement in the environmental situation for the entire basin. Meeting the environmental flows in the most upstream control points, VMc and $\mathrm{VMd}$, increases significantly the environmental flows in all the control points evaluated. The improvements can be listed as follows:

a) Increase in the period of time the environmental needs are met (Reliability);

b) Increase in the resilience of the environmental flows; the system was able to recover faster when it fails; and

c) Decrease in the environmental flows deficit (Vulnerability). When the system was not able to deliver the environmental requirements, the failure was smaller than in the actual conditions.

3. Even though the environmental requirements can be improved significantly, it will not be satisfied completely by the alternative policies proposed. The results showed that not all the times the environmental requirements will be met because during drought periods, there is not enough water in the reservoirs systems to supply the water users and the environmental needs.

4. The policies proposed in the environmental scenario will affect irrigation district 005 Delicias with a decrease in the time this irrigation district is supplied properly and an increase in the amount of the deficits. On the contrary, the Environmental scenario will benefit the Treaty obligations by reducing the volume of the deficits and irrigation district 025 Bajo Rio Bravo by increasing the period of time this water user is supplied properly. 


\section{Recommendations}

The policies proposed in the Environmental scenario are recommended because they will improve the environmental situation of the Rio Conchos basin. However, further research is need to find out a policy that mitigates the ravages provoked to DR-005 Delicias, one of this policies may be the delivery of the water savings established in Minute 309 in an environmental pattern.

Besides, it is also necessary to determine the environmental flow requirements in other parts of the Rio Grande/Bravo basin, such as the Big Bend area. The determination of these flow requirements in other regions will make possible the evaluation of the environmental faith with the actual water management policies and will also make possible the proposition of alternative water management policies that can improve the environment situation of the basin.

\section{Acknowledgments}

Special acknowledgement is given to Rebecca L. Teasley, Carlos Patiño Gomez, Ivonne Muñoz Gonzalez and the National Council of Science and Technology of Mexico, CONACYT. Partial funding for this research has been provided by the World Wildlife Fund of Chihuahua.

\section{References}

Danner, C. L., McKinney, D. C., and Teasley, R. L. (2006). "Documentation and Testing of the WEAP Model for the Rio Grande/Bravo Basin." CRWR Online Report 06-08.

Enriquez-Coyro, E., (1976) "El Tratado entre México y los Estados Unidos de América sobre Ríos Internacionales." Facultad de Ciencias Políticas y Sociales. Universidad Nacional Autónoma de México.

Hashimoto, T., Stedinger, J.R., and D.P. Loucks (1982). Reliability, resiliency and vulnerability criteria for water resource system performance evaluation. Water Resources Research 18 (1), 14-20.

International Boundary and Water Commission (IBWC) (1906). "Convention between the United States and Mexico. Equitable distribution of the Waters of the Rio Grande" http://www.ibwc.state.gov/Files/1906Conv.pdf

International Boundary and Water Commission (IBWC) (1944). "Treaty between the Unites States of America and Mexico.” www.ibwc.state.gov/Files/1944Treaty.pdf

Loucks D. P. and E. van Beek (2005). Water Resources Systems Planning and Management. UNESCO

Natural Heritage Institute (2001). "A Physical Assessment of the Opportunities for Improved Management of the Water Resources of the Bi-National River Basin" (December 28, 2006)

McMahon, T. A., Adoloye, A.J. and S. Zhou (2006). Understanding performance measures of reservoirs Jounal of Hydrology 324 (2006) 359-382. 
Natural Heritage Institute (2006). "Water Management Scenarios for the Rio Grande/Bravo basin from the Rio Conchos to the Gulf." San Francisco CA. (October $3^{\text {rd }}, 2006$ )

Patiño-Gomez, C., and D. McKinney (2005). "GIS for Large-Scale Watershed Observational Data Model." CRWR Online Report 05-07, Center for Research in Water Resources, University of Texas at Austin.

Pegasys Consulting (2007). The Rio Conchos Basin - Basin Allocation Assessment. January 2007.

Physical Assessment Project (PAP 2006), A Physical Assessment of the Opportunities for Improved Management of the Water Resources of the BiNational Rio Grande/Rio Bravo Basin: Recent Project Accomplishments, 2006, www.riogrande-riobravo.org/Documents/Project\%20Accomplishments.pdf

Sandoval-Solis, S., McKinnaey, D.C. and H. Sanvicente-Sanchez. Evaluation of Water Management Scenarios for the Rio Grande/Bravo. Proceedings World Environmental and Water Resources Congress 2008. Honolulu Hawaii.

Texas Commission on Environmental Quality (TCEQ) (1939). Rio Grande Compact.

Water Code, Title 3, Chapter 41. http://tlo2.tlc.state.tx.us/statutes/docs/WA/content/pdf/wa.003.00.000041.00.pdf

World Wildlife Fund (2006). "Conclussions from the Building Block Method specialist work session Rio Conchos" February $27^{\text {th }}$ to March $1^{\text {st }}, 2006$. 